\title{
Spinal epidural hematoma and abscess after neuraxial anesthesia: a historical cohort study using the Japanese Diagnosis Procedure Combination database \\ Hématomes et abcès périduraux après une anesthésie neuraxiale : une étude de cohorte historique fondée sur la base de données japonaise DPC
}

\author{
Kanako Makito, MD, MPH • Hideyuki Mouri, MD, MPH • Hiroki Matsui, MPH • \\ Nobuaki Michihata, MD, PhD • Kiyohide Fushimi, MD, PhD • Hideo Yasunaga, MD, PhD
}

Received: 23 January 2020/Revised: 12 July 2020/ Accepted: 13 July 2020/Published online: 9 October 2020

(C) Canadian Anesthesiologists' Society 2020

\begin{abstract}
Background Spinal epidural hematoma and abscess are rare complications of neuraxial anesthesia but can cause severe neurologic deficits. The incidence of these complications vary widely in existing studies and the risk factors remain uncertain. We estimated the incidence of these complications and explored associations using a national inpatient database in Japan.

Methods Using Japanese Diagnosis Procedure Combination data on surgical inpatients who underwent neuraxial anesthesia from July 2010 to March 2017, we identified patients with spinal epidural hematoma and/or abscess. We investigated age, sex, Charlson comorbidity index, antithrombotic therapy, type of surgery, admission, and hospital for association with these complications. The incidences of spinal epidural hematoma and abscess were estimated separately, and a nested case-control study was performed to examine factors associated with these complications.
\end{abstract}

K. Makito, MD, MPH $(\bowtie) \cdot H$. Matsui, MPH $\cdot$ N. Michihata , MD, $\mathrm{PhD} \cdot \mathrm{H}$. Yasunaga, MD, $\mathrm{PhD}$

Department of Clinical Epidemiology and Health Economics, School of Public Health, The University of Tokyo, Tokyo, Japan e-mail: canakana87@m.u-tokyo.ac.jp

H. Mouri, MD, MPH

Department of Anesthesiology and Intensive Care Medicine,

Kanazawa University, Kanazawa, Japan

K. Fushimi, MD, PhD

Department of Health Policy and Informatics, Graduate School of Medicine, Tokyo, Medical and Dental University, Tokyo, Japan
Results We identified 139 patients with spinal epidural hematoma and/or abscess among 3,833,620 surgical patients undergoing neuraxial anesthesia. The incidences of spinal epidural hematoma and abscess were 27 (95\% confidence interval [CI], 22 to 32) and 10 (7 to 13) per one million patients, respectively. Spinal anesthesia was associated with significantly fewer complications compared with epidural or combined spinal epidural anesthesia (odds ratio, 0.15; 95\% CI, 0.08 to 0.32). Antiplatelet agent (odds ratio, 0.49; 95\% CI, 0.06 to 3.91) and anticoagulants (odds ratio, 1.65; $95 \%$ CI, 0.95 to 2.85) were not significantly associated with these complications. Conclusions This analysis identified the incidences of spinal epidural hematoma and/or abscess after neuraxial anesthesia. Additional large-scale studies are warranted to examine the incidences and factors associated with these complications.

\section{Résumé}

Contexte Les hématomes et abcès périduraux sont des complications rares de l'anesthésie neuraxiale qui peuvent toutefois provoquer des atteintes neurologiques graves. L'incidence de ces complications est très variable dans les études existantes et les facteurs de risque demeurent incertains. Nous avons estimé l'incidence de ces complications et exploré les associations en analysant une base de données nationale des patients hospitalisés au Japon.

Méthode En nous fondant sur la base de données japonaise Diagnosis Procedure Combination (DPC - un système de paiement des soins de santé uniformisé) de juillet 2010 et mars 2017, nous avons identifié les patients 
chirurgicaux hospitalisés ayant reçu une anesthésie neuraxiale et ayant souffert d'un hématome et/ou d'un abcès péridural. Nous avons examiné l'âge, le sexe, l'indice de comorbidité de Charlson, le traitement antithrombotique, le type de chirurgie, l'admission et l'établissement pour déterminer si ces facteurs étaient associés à ces complications. Les incidences d'hématomes et d'abcès périduraux rachidiens ont été séparément estimées, et une étude cas témoins imbriquée a été réalisée pour examiner les facteurs associés à ces complications.

Résultats Nous avons identifié 139 patients ayant souffert d'un hématome et/ou d'un abcès péridural parmi les 3833620 patients chirurgicaux ayant reçu une anesthésie neuraxiale. Les incidences d'hématome et d'abcès périduraux rachidiens étaient de 27 (intervalle de confiance [IC] $95 \%, 22$ à 32) et 10 (7 à 13) par million de patients, respectivement. La rachianesthésie était associée à un nombre significativement plus faible de complications comparativement à une anesthésie péridurale ou péridurale rachidienne combinée (rapport de cotes, 0,15; IC 95 \%, 0,08 à 0,32). Aucune association significative n'a été observée entre les agents antiplaquettaires (rapport de cotes, 0,49; IC $95 \%, 0,06$ à 3,91) ou les anticoagulants (rapport de cotes, 1,65; IC 95 $\%, 0,95$ à 2,85) et ces complications.

Conclusion Cette analyse a identifié les incidences d'hématome et/ou d'abcès péridural après une anesthésie neuraxiale. Des études supplémentaires de grande envergure sont nécessaires pour examiner les incidences et les facteurs associés à ces complications.

Keywords neuraxial anesthesia

spinal epidural hematoma $\cdot$ spinal epidural abscess

Spinal epidural hematoma and spinal epidural abscess after neuraxial anesthesia are rare but severe complications. Expanded hemorrhage and abscess in the spinal canal may lead to permanent paraplegia from spinal cord ischemia and infarction.

Reports of the incidences of spinal epidural hematoma after neuraxial anesthesia vary widely in existing studies. Based on previous studies, the estimated incidence of spinal epidural hematoma is approximately one per 220,000 cases of spinal anesthesia (SA) and one per 150,000 cases of epidural anesthesia (EA) among patients who did not receive thromboprophylaxis. ${ }^{1-3}$ A multicentre study conducted in Sweden from 1990 to 1999 showed that spinal epidural hematoma and abscess occurred, respectively, in 33 and 13 of approximately $1,710,000$ patients $(1,260,000 \mathrm{SA}$ and $450,000 \mathrm{EA}$ or combined spinal epidural anesthesia [CSEA]) and in two and one of 255,000 obstetric patients $(200,000$ EA or CSEA for pain relief during labour, 5,000 EA and 50,000 SA for Cesarean deliveries) and that spinal epidural hematoma occurred in one of 3,600 older female patients undergoing knee arthroplasty with EA. ${ }^{4}$ A study based on patient insurance claims from 1987 to 1993 in Finland found that spinal epidural hematoma and abscess occurred, respectively, in five and two of 720,000 patients $(550,000$ SA and 170,000 EA). ${ }^{5}$ Anesthesia and clinical practice evolve over time, and it is therefore essential to know the recent trends in these severe complications after neuraxial anesthesia.

Anesthesiologists must make careful decisions regarding whether to perform neuraxial anesthesia, considering its benefits and risks. In this context, it is important to know the risk factors for spinal epidural hematoma and spinal epidural abscess, which can help anesthesiologists to perform neuraxial anesthesia safely and to avoid complications. Nevertheless, such information has been lacking.

In the present study, using a national inpatient database in Japan, we examined the incidences of spinal epidural hematoma and spinal epidural abscess after neuraxial anesthesia, as well as the potential risk factors for these complications.

\section{Methods}

This study was exempted from obtaining informed consent because of the anonymous nature of the data. Study approval was obtained from the Institutional Review Board at the University of Tokyo (20 October 2011).

\section{Data source}

Inpatient data were extracted from the Japanese Diagnosis Procedure Combination (DPC) database. The details of the DPC database have been described elsewhere. ${ }^{6}$ Briefly, the DPC database includes data on approximately seven million inpatients per year from over 1,000 hospitals, representing approximately $50 \%$ of all inpatient admissions to acute care hospitals in Japan. ${ }^{7}$ The DPC database contains administrative claims data and the following detailed patient data: age; sex; body mass index; diagnoses, comorbidities at admission, and complications after admission recorded as text data in Japanese and coded using International Classification of Diseases and Related Health Problems, 10th Revision (ICD-10) codes; surgical procedures coded using the original Japanese codes; drugs used during hospitalization; length of stay; Barthel index; and discharge status. 
The Charlson comorbidity index was calculated for each patient, based on the ICD-10 diagnosis codes. The Charlson comorbidity index is widely used as a validated measure to predict in-hospital morbidity and mortality. ${ }^{8}$

The Barthel index measures the extent to which a person can function independently and has mobility in their activities of daily living, which include feeding, bathing, grooming, dressing, bowel control, bladder control, using the toilet, chair transfer, ambulation, and stair climbing. The items assessing bathing and grooming are scored 0 or 5. Feeding, dressing, bowel control, bladder control, using the toilet, and stair climbing are scored 0,5 , or 10 . The items regarding chair transfer and ambulation are scored 0 , 5,10 , or 15 . The total Barthel index is a cumulative score of the ten items, with a maximum score of 100 corresponding to complete independence and a minimum score of 0 corresponding to total dependence. We categorized the Barthel index score as 0-40, 45-95, or 100 , indicating total or severe dependence, moderate dependence, and independence, respectively.

All data for each patient are recorded at discharge. To optimize the accuracy of the recorded diagnoses, the physicians in charge are obliged to record the diagnoses with reference to medical charts. Licensed medical information managers and trained medical clerks accurately record the dates of all major and minor procedures and of the drugs and devices used. Because the entry of accurate data are mandatory for reimbursement of medical fees, hospitals have a strong incentive to comply with these rules. ${ }^{7}$

\section{Data extraction}

From the DPC database, we obtained records on all patients undergoing neuraxial anesthesia, including SA, EA, and CSEA, during hospitalization from 1 July 2010 to 31 March 2017. Our study was based on the secondary use of routinely collected clinical data, and we used a fixed, available sample. We identified only patients who underwent surgical procedures to investigate postoperative complications.

We extracted information on age; sex; length of stay; surgical procedures with neuraxial anesthesia; use of anticoagulant agents including unfractionated heparin, low molecular weight heparin, warfarin, anti-factor Xa agents, and direct thrombin inhibitors; use of antiplatelet agents including thienopyridines and other drugs (cilostazol, dipyridamole, beraprost, limaprost, sarpogrelate, and trapidil); use of nonsteroidal antiinflammatory drugs (NSAIDs); comorbidities at admission; type of admission (emergency or elective); type of hospital (academic or non-academic); Barthel index at discharge; and discharge status. NSAIDs included aspirin and other NSAIDs (sodium salicylate, mefenemic acid, flufenamic acid aluminum, diclofenac sodium, amfenac sodium hydrate, indometacin, indometacin farnesil, acemetacin, proglumetacin maleate, sulindac, mofezolac, etodolac, nabumetone, ibuprofen, flurbiprofen, flurbiprofen axetil, ketoprofen, naproxen, pranoprofen, tiaprofenic acid, oxaprozin, loxoprofen sodium hydrate, zaltoprofen, piroxicam, ampiroxicam, lornoxicam, meloxicam, celecoxib, tiaramide hydrochloride, epirizol, and emorfazone).

Surgical procedures were categorized into (i) gastrocolic, hepatobiliary, and pancreatic surgery; (ii) thoracic surgery (lung, esophagus, and breast surgery); (iii) vascular surgery (thoracic, abdominal, and peripheral vascular surgery); (iv) obstetric surgery; (v) gynecological surgery; (vi) orthopedic surgery; (vii) urological surgery; and (viii) plastic surgery. Obstetric surgery included all surgeries related to pregnancy except for labour analgesia (e.g., Cesarean delivery, abortion, ectopic pregnancy surgery, circumferential suture of cervix, and uterine rupture surgery).

We excluded patients less than $20 \mathrm{yr}$ of age because a previous study showed no spinal epidural hematoma and only one spinal epidural abscess following more than 100,000 cases of regional anesthesia in children. ${ }^{9}$ Patients undergoing multiple surgical procedures with neuraxial anesthesia were excluded because the DPC database lacks information on the timing of the occurrence of spinal epidural hematoma and/or abscess. We therefore could not identify after which type of anesthesia spinal epidural hematoma and/or abscess occurred during the same admission.

Spinal epidural hematoma and abscess

We searched for patients with recorded diagnoses of comorbidities after admission that included both "epidural" and "hematoma" in the textual data. Of the identified patients, we included those who also had "lumbar," "thoracic," or "spinal" in the diagnosis. We excluded patients with "cervical" or "intracranial" in their diagnosis. We did not use ICD-10 codes to identify spinal epidural hematoma because the codes corresponding to spinal epidural hematoma include other diseases; for example, T093 includes spinal shock, spinal cord contusion, and spinal cord trauma in addition to spinal epidural hematoma. We identified patients with spinal epidural abscess using ICD-10 codes G061 (intraspinal abscess and granuloma) and G062 (extradural and subdural abscess, unspecified) in complications after admission. We also searched for spinal epidural abscess using the phrase "epidural abscess" (koumakugai-nouyou in Japanese) in the patients' comorbidities after admission. We then 
Figure Incidence of spinal epidural hematoma and/or abscess in 2010-2016

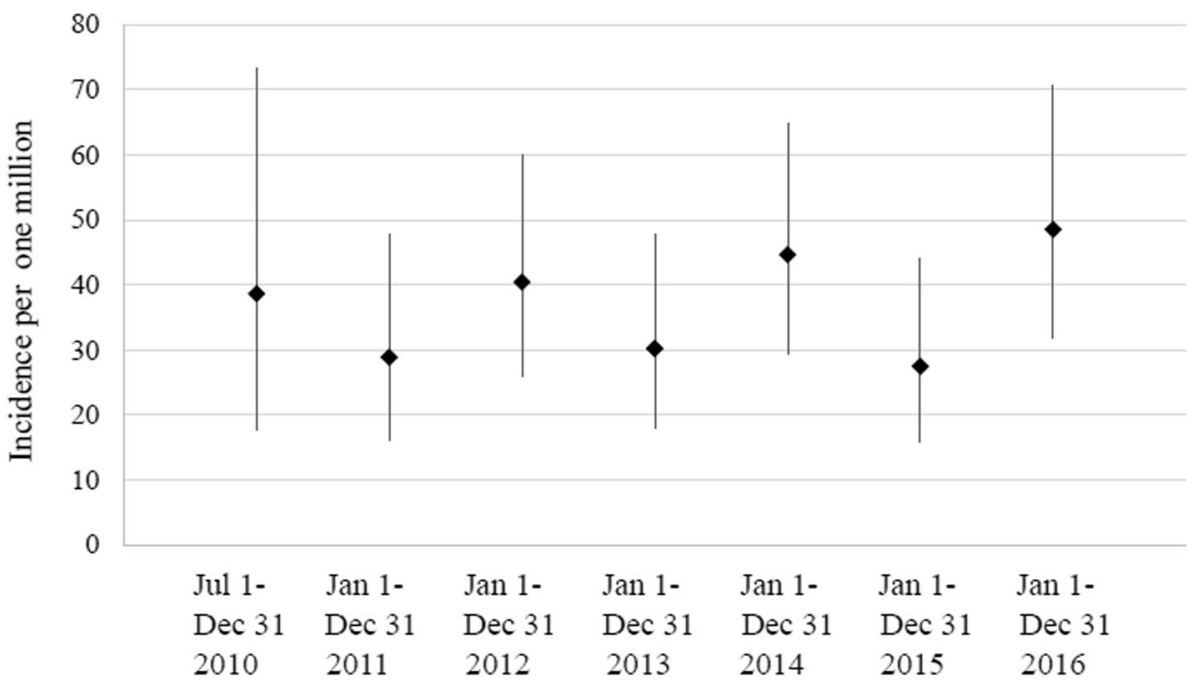

excluded patients with cervical epidural abscess or intraspinal granuloma using the terms "cervical" (keibu in Japanese) and "granuloma" (nikugesyu in Japanese). Patients with both spinal epidural hematoma and abscess were identified when patients diagnosed with spinal hematoma had spinal epidural abscess. Two researchers performed these search procedures and obtained the same results.

We could not identify the accurate date of administration or cessation of NSAIDs or antithrombotic medications (antiplatelet agents and anticoagulants). Therefore, we examined the prescription of these medications within one week before and one week after the surgical procedure as variables associated with spinal epidural hematoma and/or abscess. We examined the number of patients with spinal epidural hematoma requiring decompressive laminectomy within five days after neuraxial anesthesia.

\section{Statistical analysis}

Data on patient characteristics, type of hospital, and surgical procedures are summarized as numbers and percentages by type of anesthesia. A Chi squared test was used to compare the incidences of spinal epidural hematoma and/or abscess in different years.

We conducted a nested case-control study with a conditional univariable logistic regression model to examine the associations of neuraxial complications with Charlson comorbidity index, type of admission, type of neuraxial anesthesia, type of surgical procedure, use of NSAIDs, and use of antithrombotic medications. For each case, we randomly selected five controls matched with similar age ( \pm five years) and the same sex from the same hospital in the same year. $P$ values $<0.05$ were considered statistically significant. All of the analyses were conducted using SPSS, Version 25.0 (Chicago, IL, USA) and Stata/ MP 15.0 (Stata Corp., College Station, TX, USA).

\section{Results}

During the study period, 4,096,238 patients who underwent neuraxial anesthesia for the purpose of surgical analgesia were identified. After excluding patients aged under $20 \mathrm{yr}$ $(n=111,179)$ and those who underwent multiple surgical procedures with neuraxial anesthesia ( $n=262,618)$, 3,833,620 eligible patients remained.

Overall, 103 patients with spinal epidural hematoma and 37 patients with spinal epidural abscess were identified. One patient suffered from both spinal epidural hematoma and abscess; therefore, the number of patients with spinal hematoma and/or abscess was 139. The incidence of spinal epidural hematoma and abscess were 27 events per one million cases (95\% confidence interval [CI], 22 to 32) and ten events per one million (95\% CI, 7.0 to 13.0) cases of neuraxial anesthesia, respectively. The Figure shows no significant difference in the incidence by year $(P=0.49)$.

A total of 26 patients $(25.2 \%)$ with spinal epidural hematoma received decompressive laminectomy within five days after the surgical procedure. Table 1 summarizes the studies describing incidence of spinal epidural hematoma and abscess following neuraxial anesthesia. Table 2 shows patient characteristics, type of hospital, and surgical procedures.

Table 3 shows the results of the conditional univariable logistic regression analysis within the nested case-control data. We identified 675 patients in the control group who were matched with 139 cases. Spinal anesthesia was associated with significantly fewer occurrences of spinal epidural hematoma and/or abscess compared with EA or CSEA (odds ratio, $0.15 ; 95 \% \mathrm{CI}, 0.08$ to 0.32 ). Use of 


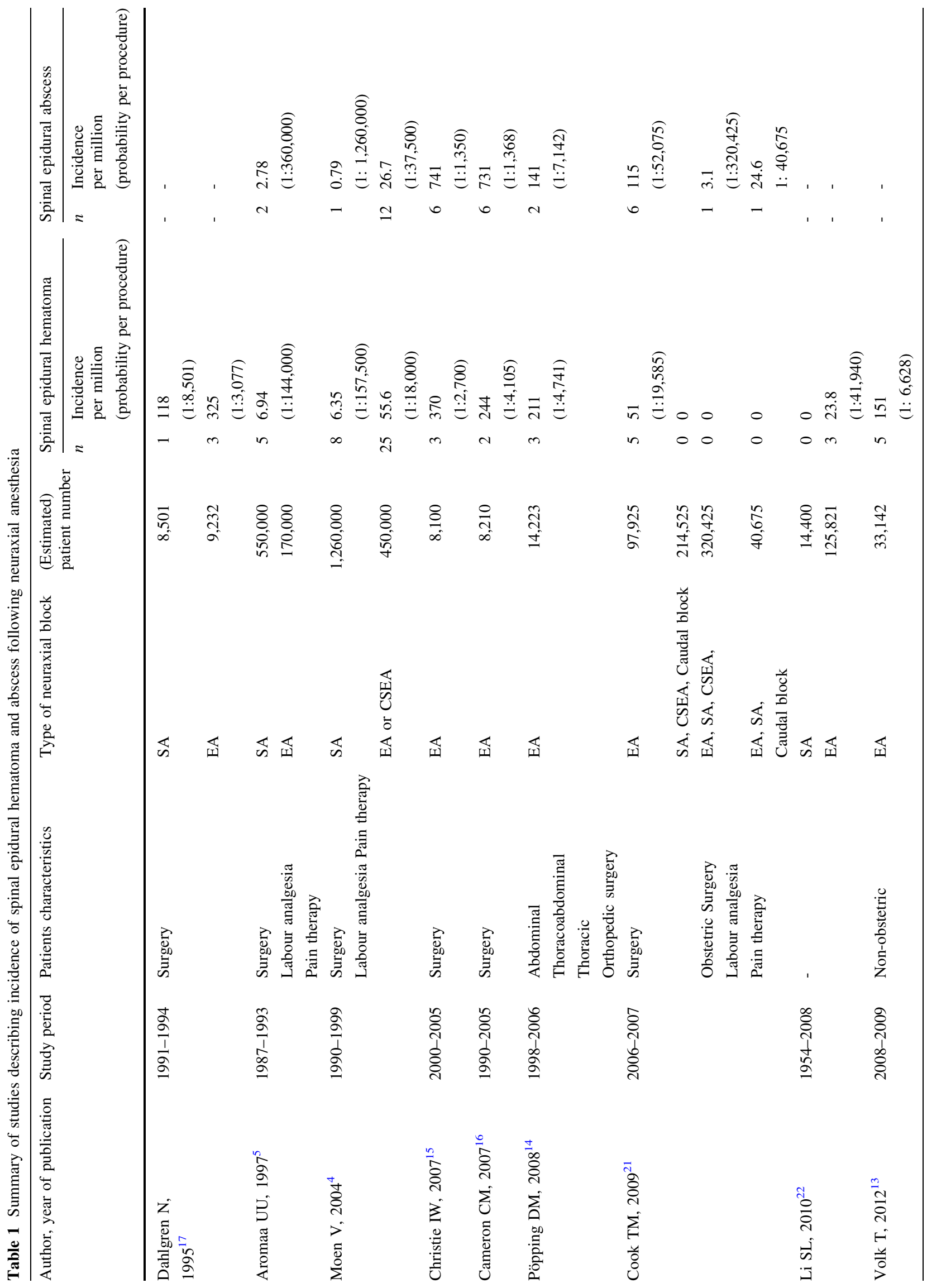




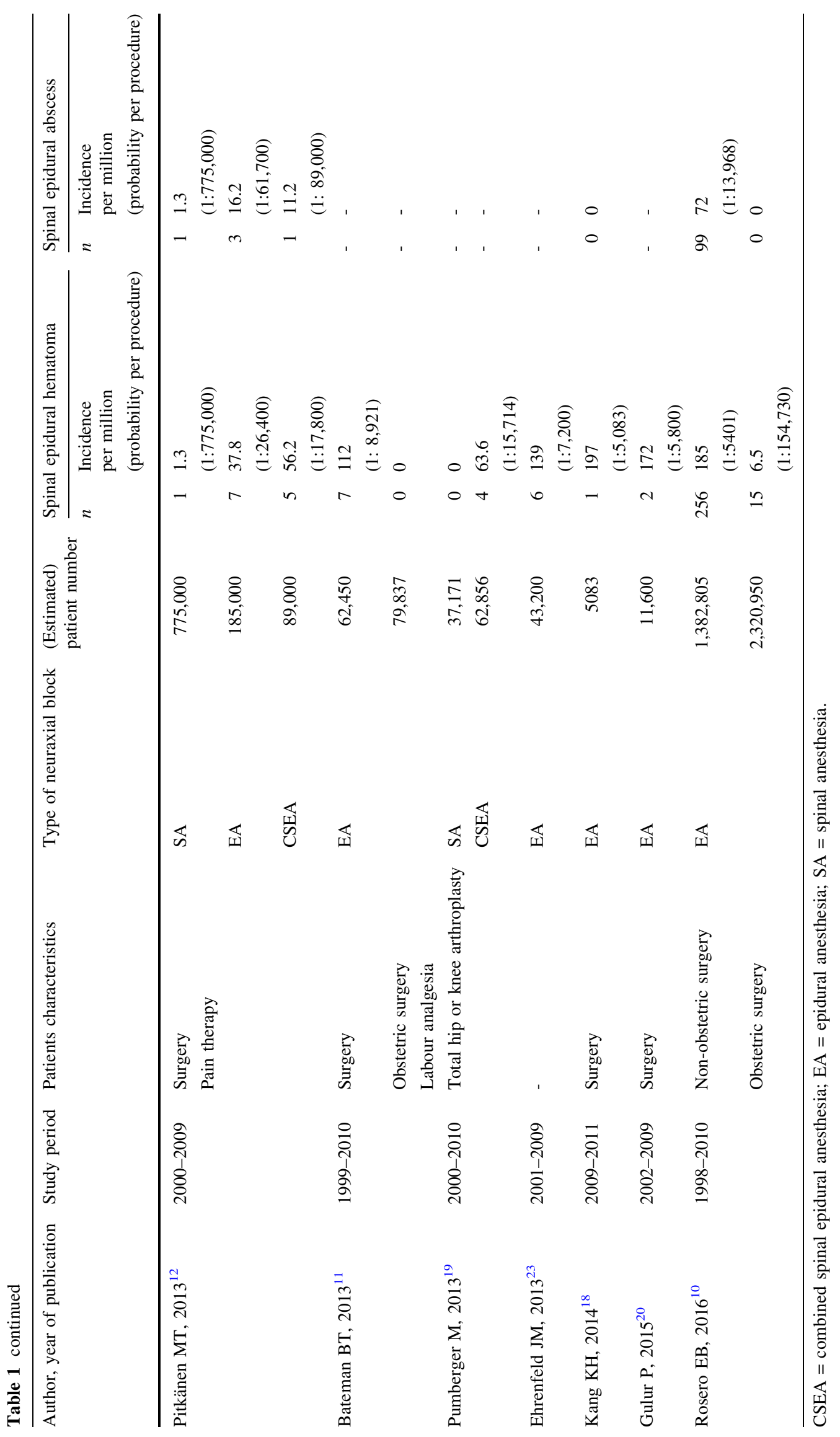




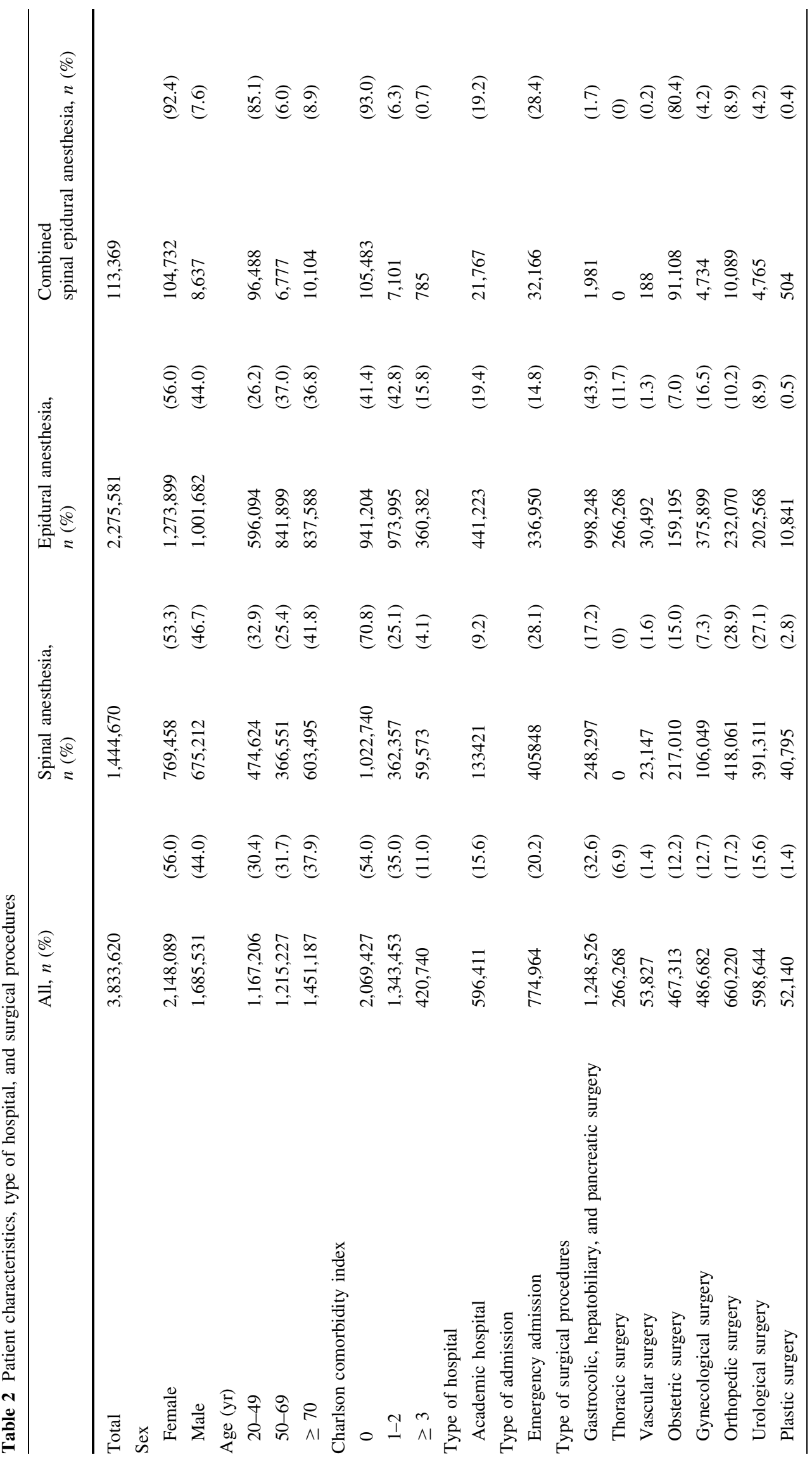


Table 3 Univariable conditional logistic regression analyses for spinal epidural hematoma and/or abscess in the nested case-control study

\begin{tabular}{|c|c|c|c|}
\hline Characteristics & \multicolumn{2}{|c|}{$\begin{array}{l}\text { Odds ratio } \\
\text { ( } 95 \% \text { confidence interval) }\end{array}$} & $P$ value \\
\hline \multicolumn{4}{|l|}{ Charlson comorbidity index } \\
\hline 0 & Ref & & \\
\hline $1-2$ & 1.12 & $(0.69$ to 1.80$)$ & 0.65 \\
\hline$\geq 3$ & 1.64 & $(0.91$ to 2.96$)$ & 0.10 \\
\hline \multicolumn{4}{|l|}{ Type of admission, $n(\%)$} \\
\hline Emergency admission & 0.85 & $(0.52$ to 1.39$)$ & 0.51 \\
\hline \multicolumn{4}{|l|}{ Type of neuraxial anesthesia, $n(\%)$} \\
\hline Spinal anesthesia & 0.15 & $(0.08$ to 0.32$)$ & $<0.001$ \\
\hline Epidural anesthesia or combined spinal and epidural anesthesia & Ref & & \\
\hline \multicolumn{4}{|l|}{ Type of surgical procedures, $n(\%)$} \\
\hline Gastrocolic, hepatobiliary, and pancreatic surgery & 1.43 & $(0.94$ to 2.16$)$ & 0.09 \\
\hline Thoracic surgery & 0.77 & $(0.40$ to 1.48$)$ & 0.44 \\
\hline Vascular surgery & 3.30 & (1.04 to 10.51$)$ & 0.04 \\
\hline Obstetric surgery & 1.27 & $(0.44$ to 3.70$)$ & 0.66 \\
\hline Gynecological surgery & 1.27 & (0.63 to 2.57$)$ & 0.50 \\
\hline Orthopedic surgery & 0.68 & $(0.36$ to 1.28$)$ & 0.23 \\
\hline Urological surgery & 0.50 & $(0.25$ to 1.01$)$ & 0.06 \\
\hline Plastic surgery & 0.56 & $(0.07$ to 4.39$)$ & 0.58 \\
\hline \multicolumn{4}{|l|}{ Antithrombotic medications } \\
\hline Nonsteroidal anti-inflammatory drugs & 0.80 & (0.53 to 1.19$)$ & 0.27 \\
\hline Antiplatelet agents & 0.49 & $(0.06$ to 3.91$)$ & 0.50 \\
\hline Anticoagulants & 1.65 & $(0.95$ to 2.85$)$ & 0.08 \\
\hline
\end{tabular}

Ref $=$ reference.

antiplatelet agents (odds ratio, $0.49 ; 95 \% \mathrm{CI}, 0.06$ to 3.91 ) and anticoagulants (odds ratio, 1.65; 95\% CI, 0.95 to 2.85 ) were not significantly associated with the occurrence of spinal epidural hematoma and/or abscess.

Table 4 shows the Barthel index at discharge and the discharge status of patients with spinal epidural hematoma and/or abscess. Eighty-three patients (59.7\%) with Barthel index scores of 100 and 103 patients (74.1\%) were discharged home.

\section{Discussion}

In the current study using the Japanese DPC database, the estimated incidences of spinal epidural hematoma and spinal epidural abscess related to neuraxial anesthesia were 27 events (95\% CI, 22 to 32) per one million and ten (95\% CI, 7.0 to 13.0) per one million, respectively. This study also found that patients who underwent SA were less likely to suffer from spinal epidural hematoma and/or abscess compared with those who underwent EA or CSEA. Use of antithrombotic drugs was not significantly associated with these complications. These findings were comparable to those in previous studies. ${ }^{4,5,10-23}$
The incidences of spinal epidural hematoma and/or abscess are affected by the methods of identifying patients with these complications (numerator data) and the size of whole population (denominator data). We believe that the denominator data in the present study are accurate and reliable because a previous validation study of the DPC database used in this study showed high sensitivity and specificity of the records of procedures in the DPC database. ${ }^{6}$ For the numerator data, we identified spinal epidural hematoma and/or abscess using both the Japanese text and ICD-10 codes; therefore, our results are more valid than those obtained using only the ICD-10 codes. This study also had a large number of patients, which allowed us to identify a sufficient number of patients with these rare complications.

Previous studies have suggested that the increased incidences of spinal epidural hematoma and/or abscess were possibly due to population aging and advancements in diagnostic imaging technology. ${ }^{3}$ A previous review of the literature from 1906 to 1994 reported 61 cases of spinal epidural hematoma associated with neuraxial anesthesia, of which 53 patients had either hemostatic abnormality or difficulty in needle placement. ${ }^{2}$ In the 2000s, Cook et al. reported that spinal epidural hematoma and abscess leading 
Table 4 Postoperative status of patients with spinal epidural hematoma and/or abscess

\begin{tabular}{lll}
\hline & $\begin{array}{l}\text { Spinal epidural } \\
\text { hematoma and/or } \\
\text { abscess } n(\%)\end{array}$ \\
\hline $\begin{array}{l}\text { Total } \\
\text { Barthel index at discharge }\end{array}$ & 139 \\
100 & 83 \\
$45-95$ & 19 & $(59.7)$ \\
$0-40$ & 20 \\
Missing & 17 \\
Discharge status & 103 \\
Discharged to home & 27 \\
Transferred to other hospital & 5 & $(14.4)$ \\
Discharged to other healthcare facility & 4 & $(12.2)$ \\
Death & & \\
\hline
\end{tabular}

to permanent harm or death occurred in five of 97,925 surgical patients (one per 19,585 patients) after EA and six of 312,450 surgical patients (one per 52,075 patients) after central neuraxial block (EA, SA, CSEA, or caudal block), using the British national census. ${ }^{21}$ Another multicentre study, conducted in 2013, reported that seven of 62,450 (one per 8,921 cases) patients undergoing perioperative epidural catheterization developed spinal epidural hematoma. ${ }^{11}$ A retrospective cohort study conducted from 1954 to 2008 with a Chinese population reported the total number of spinal epidural hematoma cases to be three of 140,221 (one per 46,740 patients) after neuraxial anesthesia. ${ }^{22}$ These studies may have underestimated the true incidences of spinal epidural hematoma and abscess because the samples or studied populations were small.

In contrast, Rosero et al. reported that the numbers (incidences) of spinal epidural hematoma and abscess after EA were $256(18.5$ per 100,000) and $99(7.2$ per 100,000), respectively, of a total of $1,382,805$ non-obstetric patients. The numbers (incidences) of spinal epidural hematoma and abscess were $15(0.6$ per 100,000$)$ and 0 , respectively, of a total of 2,320,950 obstetric patients. ${ }^{10}$ The studied patient population size in this previous study $(n=3,703,755)$ was similar to that in the present study. We did not calculate the incidences of these complications in obstetric (e.g., Cesarean delivery) and non-obstetric patients separately. Nevertheless, even if we calculated the incidence in nonobstetric patients, the estimated incidence would be lower than those in this previous study. This difference may be attributable to differences in patient characteristics between the two studies; the previous study focused on both surgical and non-surgical patients undergoing EA, whereas we analyzed only surgical patients undergoing neuraxial anesthesia. Practice patterns regarding antithrombotic agents may also have differed between the two studies.
The present guidelines for regional anesthesia recommend perioperative cessation of NSAIDs and antithrombotic medications. ${ }^{3,24-26}$ Nevertheless, these guidelines are based on limited clinical evidence from only case series studies and expert opinions. Compliance with the guidelines may vary across different countries; our results showed that approximately two-thirds of patients used NSAIDs during the perioperative period. Our study did not show a significant association between perioperative use of antithrombotic agents and the occurrence of spinal epidural hematoma or abscess. This may be due to a lack of statistical power because of the small numbers of patients who used perioperative antithrombotic agents.

A previous study using the American Society of Anesthesiologists Closed Claims Database in the 1980s and 1990s showed that more than half of 36 patients with spinal epidural hematoma underwent vascular surgery. ${ }^{27}$ We could not compare our results with those of this previous study because the previous study did not examine the incidence of spinal epidural hematoma and abscess; however, our findings showed the highest number of patients with these complications among those who underwent gastrocolic, hepatobiliary, or pancreatic surgical procedures. Of vascular surgical patients, only five experienced these complications.

The present study has several limitations. First, recorded diagnoses may have lower sensitivity compared with those in chart reviews. A previous validation study of the DPC database used in this study showed moderate sensitivity and high specificity of the recorded diagnoses of several common diseases, including malignant tumour, cardiac diseases, stroke, and renal diseases. ${ }^{6}$ Nevertheless, we believe that validation studies for rare diseases are generally impossible; therefore, the validity of the diagnoses of spinal epidural hematoma and abscess remain uncertain in this study. Second, the DPC database does not include cases for which lawsuits were filed because the healthcare costs for such cases are not reimbursed by universal health insurance in Japan. Nevertheless, according to the website of the Supreme Court of Japan, ${ }^{28}$ of 5,778 malpractice suits (judgements/ settlements) from 2011 to 2017 across Japan, only 44 cases were related to anesthesia. We therefore believe that the number of legal cases related to spinal epidural hematoma and/or abscess was extremely small and that our findings would not be changed by their inclusion in the study. Third, information was not available on several factors that were potentially associated with the complications, including underlying hemostatic abnormalities, difficulty during needle or catheter placement (due to spinal anatomic abnormalities or skill differences among anesthesiologists), specific details of anticoagulant administration, timing of 
spinal epidural hematoma and/or abscess occurrence, and incidence of permanent neurologic sequelae. Finally, the DPC database included approximately $50 \%$ of all inpatient data for acute care hospitals in Japan, but the participation of community hospitals in the DPC database was voluntary. This may have restricted the population representativeness of the study; because of this selection bias, selected patients may have had higher risks compared with the entire population.

In conclusion, this retrospective observational study using a large-scale national database revealed the incidences of spinal epidural hematoma and abscess. The incidences of these complications were extremely low, so we could not identify factors associated with these complications. Additional large-scale studies are warranted to examine associated factors.

Author contributions Kanako Makito contributed to all aspects of this manuscript, including study conception and design; analysis and interpretation of data; and drafting the article. Hideyuki Mouri contributed to conception and design of the study and analysis of data. Nobuaki Michihata contributed to the analysis of data. Hiroki Matsui contributed to the compilation of data. Kiyohide Fushimi contributed to the acquisition of data. Hideo Yasunaga contributed to the acquisition of data; the conception and design of the study; interpretation of data; and supervision of this research project

\section{Disclosures None.}

Funding statement This work was supported by grants from the Ministry of Health, Labour and Welfare, Japan (19AA2007 and H30Policy-Designated-004) and the Ministry of Education, Culture, Sports, Science and Technology, Japan (17H04141).

Editorial responsibility This submission was handled by Dr. Gregory L. Bryson, Deputy Editor-in-Chief, Canadian Journal of Anesthesia.

\section{References}

1. Tryba M. Epidural regional anesthesia and low molecular heparin: Pro (German). Anasthesiol Intensivmed Notfallmed Schmerzther 1993; 28: 179-81.

2. Vandermeulen EP, Van Aken H, Vermylen J. Anticoagulants and spinal-epidural anesthesia. Anesth Analg 1994; 79: 1165-77.

3. Horlocker TT, Vandermeuelen E, Kopp SL, Gogarten W, Leffert $L R$, Benzon HT. Regional anesthesia in the patient receiving antithrombotic or thrombolytic therapy: American Society of Regional Anesthesia and Pain Medicine Evidence-Based Guidelines (Fourth Edition). Reg Anesth Pain Med 2018; 43: 263-309.

4. Moen V, Dahlgren $N$, Irestedt L. Severe neurological complications after central neuraxial blockades in Sweden 1990-1999. Anesthesiology 2004; 101: 950-9.

5. Aromaa U, Lahdensuu M, Cozanitis DA. Severe complications associated with epidural and spinal anaesthesias in Finland 19871993. A study based on patient insurance claims. Acta Anaesthesiol Scand 1997; 41: 445-52.
6. Yamana H, Moriwaki M, Horiguchi H, Kodan M, Fushimi K, Yasunaga $H$. Validity of diagnoses, procedures, and laboratory data in Japanese administrative data. J Epidemiol 2017; 27: 47682.

7. Yasunaga H, Matsui H, Horiguchi H, Fushimi K, Matsuda S. Clinical epidemiology and health services research using the diagnosis procedure combination database in Japan. Asian Pac J Dis Manag 2016; 7: 19-24.

8. Quan H, Li B, Couris CM, et al. Updating and validating the Charlson comorbidity index and score for risk adjustment inhospital discharge abstracts using data from 6 countries. Am J Epidemiol 2011; 173: 676-82.

9. Walker BJ, Long JB, Sathyamoorthy $M$, et al. Complications in pediatric regional anesthesia: an analysis of more than 100,000 blocks from the Pediatric Regional Anesthesia Network. Anesthesiology 2018; 129: 721-32.

10. Rosero EB, Joshi GP. Nationwide incidence of serious complications of epidural analgesia in the United States. Acta Anaesthesiol Scand 2016; 60: 810-20.

11. Bateman BT, Mhyre JM, Ehrenfeld J, et al. The risk and outcomes of epidural hematomas after perioperative and obstetric epidural catheterization: a report from the Multicenter Perioperative Outcomes Group Research Consortium. Anesth Analg 2013; 116: 1380-5.

12. Pitkänen MT, Aromaa U, Cozanitis DA, Förster JG. Serious complications associated with spinal and epidural anaesthesia in Finland from 2000 to 2009. Acta Anaesthesiol Scand 2013; 57: 553-64.

13. Volk T, Wolf A, Van Aken H, Bürkle H, Wiebalck A, Steinfeldt T. Incidence of spinal haematoma after epidural puncture: analysis from the German network for safety in regional anaesthesia. Eur J Anaesthesiol 2012; 29: 170-6.

14. Pöpping DM, Zahn PK, Van Aken HK, Dasch B, Boche $R$, Pogatzki-Zahn EM. Effectiveness and safety of postoperative pain management: a survey of 18925 consecutive patients between 1998 and 2006 (2nd revision): a database analysis of prospectively raised data. Br J Anaesth 2008; 101: 832-40.

15. Christie IW, McCabe S. Major complications of epidural analgesia after surgery: results of a six-year survey. Anaesthesia 2007; 62: 335-41.

16. Cameron CM, Scott DA, McDonald WM, Davies MJ. A review of neuraxial epidural morbidity: experience of more than 8,000 cases at a single teaching hospital. Anesthesiology 2007; 106: 997-1002.

17. Dahlgren N, Törnebrandt $K$. Neurological complications after anaesthesia. A follow-up of 18,000 spinal and epidural anaesthetics performed over three years. Acta Anaesthesiol Scand 1995; 39: 872-80.

18. Kang XH, Bao FP, Xiong XX, et al. Major complications of epidural anesthesia: a prospective study of 5083 cases at a single hospital. Acta Anaesthesiol Scand 2014; 58: 858-66.

19. Pumberger M, Memtsoudis SG, Stundner O, et al. An analysis of the safety of epidural and spinal neuraxial anesthesia in more than 100,000 consecutive major lower extremity joint replacements. Reg Anesth Pain Med 2013; 38: 515-9.

20. Gulur P, Tsui B, Pathak R, Koury KM, Lee H. Retrospective analysis of the incidence of epidural haematoma in patients with epidural catheters and abnormal coagulation parameters. $\mathrm{Br} \mathrm{J}$ Anaesth 2015; 114: 808-11.

21. Cook TM, Counsell D, Wildsmith JA; Royal College of Anaesthetists Third National Audit Project. Major complications of central neuraxial block: report on the Third National Audit Project of the Royal College of Anaesthetists. Br J Anaesth 2009; 102: 179-90. 
22. $\mathrm{Li}$ SL, Wang $\mathrm{DX}, \mathrm{Ma} \mathrm{D}$. Epidural hematoma after neuraxial blockade: a retrospective report from China. Anesth Analg 2010; 111: 1322-4.

23. Ehrenfeld JM, Agarwal AK, Henneman JP, Sandberg WS. Estimating the incidence of suspected epidural hematoma and the hidden imaging cost of epidural catheterization: a retrospective review of 43,200 cases. Reg Anesth Pain Med 2013; 38: 409-14.

24. Gogarten W, Vandermeulen E, Van Aken H, et al. Regional anaesthesia and antithrombotic agents: recommendations of the European Society of Anaesthesiology. Eur J Anaesthesiol 2010; 27: 999-1015.

25. Narouze S, Benzon HT, Provenzano D, et al. Interventional Spine and Pain Procedures in Patients on Antiplatelet and Anticoagulant Medications (Second Edition: guidelines from the American Society of Regional Anesthesia and Pain Medicine, the European Society of Regional Anaesthesia and Pain Therapy, the American Academy of Pain Medicine, the International Neuromodulation
Society, the North American Neuromodulation Society, and the World Institute of Pain. Reg Anesth Pain Med 2018; 43: 225-62. 26. Japanese Society of Anesthesiologist. Regional anesthesia and nerve blocks in patients receiving antithrombotic therapy (in Japanese). Available from URL: https://anesth.or.jp/files/pdf/ guideline_kouketsusen.pdf (accessed July 2020).

27. Lee LA, Posner KL, Domino KB, Caplan RA, Cheney $F W$. Injuries associated with regional anesthesia in the 1980s and 1990s: a closed claims analysis. Anesthesiology 2004; 101: 14352.

28. Supreme Court of Japan. The number of malpractice suits (judgements/settlements) in each medical field (in Japanese). Available from URL: http://www.courts.go.jp/saikosai/vcms_lf/ 1905204shinryokamoku.pdf (accessed July 2020).

Publisher's Note Springer Nature remains neutral with regard to jurisdictional claims in published maps and institutional affiliations. 